\title{
AN INTEGRATED PRODUCTION POLICY WITH DEFECTIVE ITEMS AND STOCK-OUT BASED SUBSTITUTION UNDER TRIANGULAR DENSE FUZZY LOCK SET ENVIRONMENT
}

\author{
Snigdha Karmakar ${ }^{1}$, Sujit Kumar DE ${ }^{2}$, TApan Kumar Datta ${ }^{3}$ And \\ ADRIJIT GOSWAMI ${ }^{1, *}$
}

\begin{abstract}
Brand substitution is common observed phenomenon in daily life. It is the decision makers' economic understanding and potential scheme for business-industries. Also, it provides the flexibility in management and increases the ability to control the production. This works proposes an integrated supplier-retailer inventory model for substitutable products. Two suppliers work not works with two different brand products with their corresponding demand are involved and one retailer sells each of the products. To nullify the complexities of the joint optimization problem, we first develop a deterministic model for three cases: no substitution, partial substitution and full substitution, then we go for its fuzzification. Keeping the financial constraint of each producer, we have studied over the elasticity of the cost parameters by means of triangular dense fuzzy lock set approach with its locking and unlocking property for final decision making. Finally, sensitivity analysis and graphical illustrations are made to justify the model.
\end{abstract}

Mathematics Subject Classification. 90B06.

Received August 29, 2018. Accepted September 17, 2020.

\section{INTRODUCTION}

\subsection{General overview}

In recent years, the business industries are continuously trying to improve their business strategies with intelligent understanding. The key for an efficient business process is sophisticated planning and control strategy. The decision makers are usually handling production and logistics that often involve a high amount of complexity. In such a situation, supply chain management (SCM) promises to tackle the decision over the problem by a holystic approach. The prime aim in this approach is to optimize the overall systems: suppliers, retailers and customers with respect to the cost and service level of the entire system. Finding for an optimal solution only for the suppliers or the retailers would neither be effective nor feasible in the long term process. Banerjee [1]

Keywords. Product substitution, multiple supplier, single retailer, defective items, triangular dense fuzzy lock set, supply chain, optimization.

1 Department of Mathematics, IIT Kharagpur, Kharagpur 721302, India.

2 Department of Mathematics (UG \& PG), Midnapore College (Autonomous), Midnapore, India.

3 Department of Mathematics, BITS Pilani, Dubai Campus, Dubai, UAE.

*Correspoonding author: goswami@maths.iitkgp.ac.in 
developed a joint economic lot size model where the producer produces and delivers an order on a lot basis. Goyal [16] extended Banerjee's model and proposed a more general joint total economic-lot-size model with a lower or equal joint total relevant cost. Goyal and Gupta [17] studied the vendor-buyer coordination in integrated inventory models. Now there exists a steam of research on this topic. Soni and Patel [39] investigated an integrated inventory model with variable production rate and price sensitive demand rate and adopted the two-level trade credit policy to boost the sales and to reduce on-hand stock levels. Pal et al. [29] considered a multi-item integrated production-inventory for multiple suppliers where each supplier supplies only one raw material. Sana [34] analyzed a two stage supply chain model for promotional effort sensitive stochastic demand. Recently, Sarkar [36] considered the quantity discounts between vendor or buyer in a single set up multi-delivery supply chain model.

The traditional EOQ and EPQ model have several unrealistic assumptions like all items are perfect. Salameh and Jaber [32] developed a production inventory system where the items are of imperfect quality, not necessarily defective. They considered the items which have less acceptance quality. Goyal et al. [18] proposed a simple integrated production inventory model with imperfect item. Sarkar and Moon [37] analyzed an imperfect production inventory for stochastic demand with the effect of inflation. Sana [33] examined the effect of imperfect quality production in a three layer supply chain. Sana et al. [35] studied a supply chain model with multiple suppliers, manufacturers and retailers for both perfect and imperfect quality products. Uthayakumar and Palanivel [43] studied the effect of inflation and trade credit in an inventory model for imperfect items. De and Pal [10] considered the imperfect item in a bi-objective optimization problem. Sinha et al. [38] developed an entropic order quantity model where the demand rate is dependent on selling price and the imperfect items are being screened out.

In managing inventory stock-out is a fundamental fact that each and every manager has to face off. Wee et al. [44] developed an inventory model with shortage backordering. Ghosh et al. [15] described an EOQ model for perishable items with partial backordering (depends on waiting time) and lost sales. Hsu and Hsu [20] analyzed the shortage backordering in an imperfect integrated vendor-buyer inventory model.

Due to instability of financial market it gets much more challenge for enterprizes to provide customers with better service to adopt more market share. The concept of substitute product deals with the customers of different choices and allows them options within the industry and beyond which might fulfill the similar needs. The concept of substitution was introduced in the inventory model by Mcgillivray and Silver [25]. Parlar and Goyal [30] extended the single period problem into two-substitutable-product problem for stochastic demand. Pasternack and Drezner [31] considered a single-period problem with substitution for stochastic demand. In this sequence, Drezner et al. [14] proposed a shortage-based substitution and considered three cases such as no substitution, partial substitution and full substitution. They proved that full substitution will never give optimal decision but only partial substitution or no substitution may carry the optimal decision depending on the cost parameters itself. Also, Gurnani and Drezner [19] generalized Drezner's model for multiple substitutable products. They remodified the cost function based on run out items and obtained the optimal solution numerically. Chen et al. [4] analyzed a downward, supplier-driven substitution for perishable products and customer service objectives. Mukhopadhyay and Goswami [28] developed an EOQ model under shortages and one way substitution. They also considered the presence of imperfect quality items which are being screened out before selling to the customers. Cai et al. [3] investigated a two-echelon supply chain model with two products where the demand rate was uncertain and followed an exponential distribution. Benkherouf et al. [2] considered product substitution and time varying demand and formulated a mixed integer nonlinear program in a finite horizon inventory model. Transchel [42] examined a stochastic inventory with priced-based and stockout-based substitution and by this time Mishra [26] developed substitution cost in a deterministic inventory model for optimal order quantities.

Fuzzy set theory [45] was developed to tackle the uncertain real world problem. Since then, very often authors like Kumar et al. [23]; De and Sana [11] worked over the application of various fuzzy set in inventory management problem. Several researchers are practicing along these directions and incorporating new ideas, they are introducing new fuzzy numbers and applying in various fields. De and Sana [12] applied the hesitant 


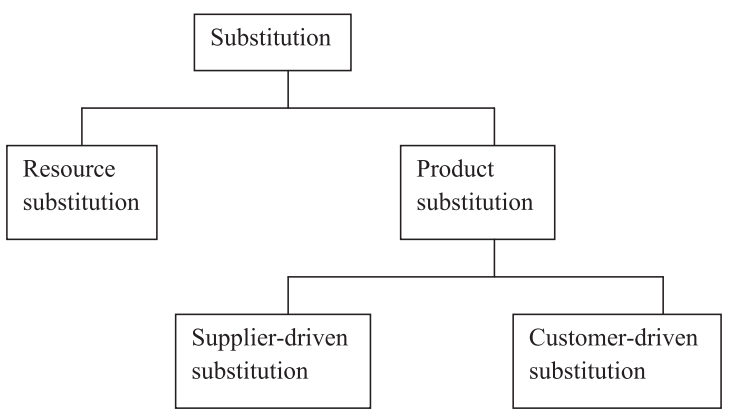

Figure 1. Substitution mechanism.

fuzzy set theory in multi-criteria multi attribute EOQ model to select the best alternatives. Incorporating the learning experience in fuzzy set theory, De and Beg [7] and De and Mahata [8] studied the triangular dense fuzzy set (TDFS) and cloudy fuzzy set for discrete and continuous variables respectively. Consequently, Karmakar et al. [22] applied the TDFS in a pollution sensitive backordered EPQ model. De [5] extended the TDFS and introduced triangular dense fuzzy lock set (TDFLS) in which the decision-maker has the full power to control the situation. De and Sana [13] proposed a two-layer supply chain model where the demand rate is assumed to be fuzzy stochastic variable with finite mean and unknown variance. Takami et al. [40] focused on two issues for a project porfolio selection model by considering hesitant fuzzy weighted averaging operator. Jamali et al. [21] formulated a supply chain management network under discrete Markov-modulated demand. Considering the demand rate as triangular fuzzy number Moghdani et al. [27] extended the EPQ model with multiple deliveries for the space constraints. De and Mahata [9] developed a three layer supply chain network model with partial backlogging and random disruptions under TDFLS environment. Maity et al. [24] discussed an inventory model with backorder under intuitionistic dense fuzzy environment. De [6] introduced the degree of fuzziness of a polygonal fuzzy set.

In this work, first we develop a deterministic two-echelon supply chain with two suppliers offer one brand each and one retailer who sells the two brands of the product. The items have been replenished simultaneously. The brands are substitutable. When a desired brand item is out of stock due to the presence of imperfectness in the product, its demand is satisfied by using the other brand products. Finally, we have assumed the cost parameters as flexible and have utilized the TDFLS rule to get a final result.

The rest of the paper is organized as follows: Section 3 provides the assumptions for the proposed model and the notation have been used throughout the paper. In Section 4, the mathematical model is formulated. Then, in Section 6, we utilize the TDFLS and a fuzzy mathematical model with a solution algorithm is developed. Also an implication of TDFLS is given in Section 5, Section 7 provides the numerical examples. Sensitivity of the parameters and some graphical illustrations have been given in Sections 8 and 9 respectively. Section 11 concludes the whole work.

\subsection{Motivation and specific study}

In the 20th century, the competitive production process have the flexibilities in logistics of decision making. Flexibility means the DM can carry out the production process in slightly different way than usual to increase the performance of a company. Substitute of products is one such flexibility which allows the DM as well as the consumers to choose different options of a particular need. There are two categories substitution process (Fig. 1) observed in the system: supplier-driven substitution and customer-driven substitution. If a supplier meets a customer's demand for a product by another product, then it is supplier-driven substitution. Alternatively, customer substitute one product by another called customer-driven substitution. 


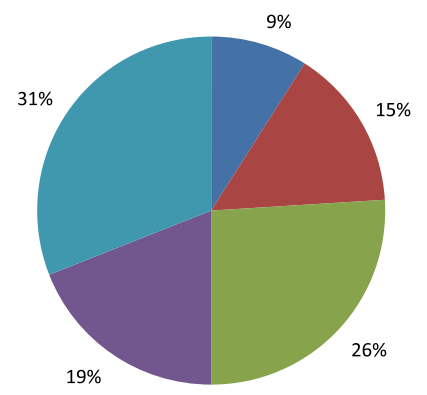

Do not purchase item

Delay purchase

- Substitute different brand

- Substitute same brand

Buy item at another store

FIgURE 2. Customers' behavior in stockout situation.

Tang and Yin [41] studied three substitution mechanism: inventory based, assortment based and priced based substitution. When a customer visits a store to buy a particular product that turns out as out of stock, the customer might be willing to substitute that product and buy another product which is inventory-based substitution (stock out situation). A recent survey about consumers' behavior in stock out situation have given in Figure 2.

The inventory-based substitution is one of the example of supplier-driven substitution also. In assortmentbased substitution, the customer chooses a substitute assuming that the substitute is newly added in the assortment. When income decreases or prices increase, the consumers replace luxury items with cheaper alternatives which is called price-based substitution. Clearly, price-based substitution is customer-driven.

However, from the existing literature on substitution, we have observed in the area of stochastic inventory control with substitution, a considerable amount of literature has been published, but often with very restrictive model assumptions that make it difficult to apply the solution approaches in practice. In this study, we wish to focus on integrated deterministic inventory model for substitutable items. The substitution occurs due to the presence of imperfect item which creates stock out in the inventory position. Recent surveys say, around $70-90 \%$ stock outs are caused by defective items. Studying this nature we have incorporated the stock out-based substitution in our work. To the best of our knowledge, no works have been done on substitution under fuzzy environment. Our contribution to the literature is shown in Figure 3.

\section{PRELiminaries}

Definition 2.1 (Triangular dense fuzzy lock set (TDFLS) [5]). Let a fuzzy number $\tilde{A}=\left(a_{1}, a_{2}, a_{3}\right)$ with $a_{1}=a_{2} f_{n}$ and $a_{3}=a_{2} g_{n}$, where $f_{n}$ and $g_{n}$ are the sequence of functions. Now if $f_{n} \rightarrow \delta_{1}(<1)$ and $g_{n} \rightarrow \delta_{2}(>1)$ (both converge) as $n \rightarrow \infty$, then the fuzzy set does not converge to a crisp singleton $\left\{a_{2}\right\}$ i.e. $\tilde{A}=\left(a_{1}, a_{2}, a_{3}\right) \nrightarrow$ $\left\{a_{2}\right\}$ and we call the triangular dense fuzzy set as TDFLS.

Example 2.2. Let us assume the component functions of a TDFLS be $f_{n}=\frac{1}{k_{1}}-\frac{1}{1+n}$ and $g_{n}=\frac{1}{k_{2}}-\frac{1}{1+n}$ then the TDFLS is given as follows:

$$
\tilde{A}=\left(a_{2}\left\{1-\rho\left(\frac{1}{k_{1}}-\frac{1}{1+n}\right)\right\}, a_{2}, a_{2}\left\{1+\sigma\left(\frac{1}{k_{2}}-\frac{1}{1+n}\right)\right\}\right), \quad \text { for } 0<\rho, \sigma<1
$$

The graphical interpretation of TDFLS is shown in Figure 4. 


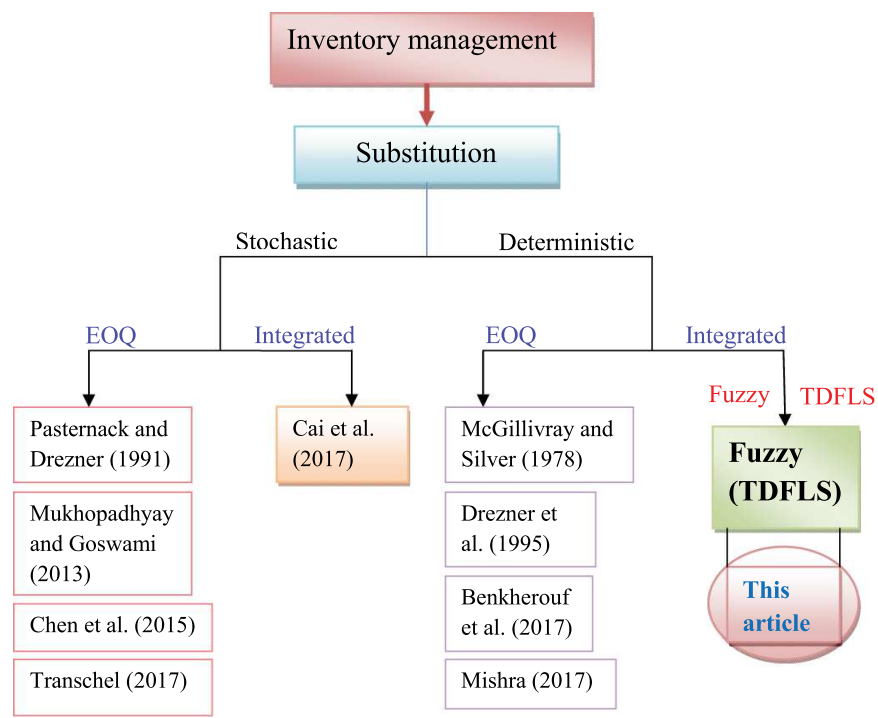

FiguRE 3. Author's contribution over contemporary research.

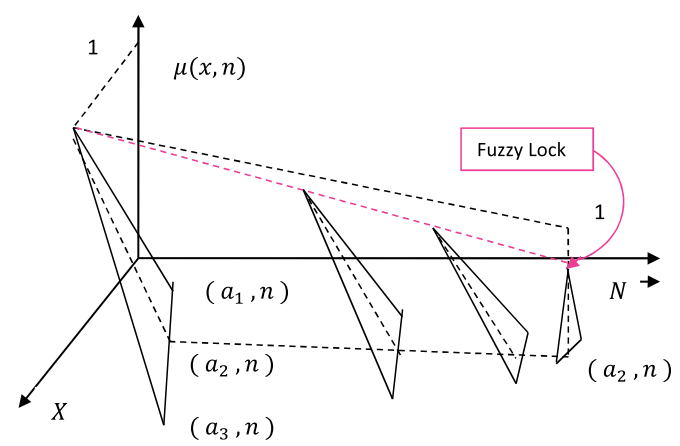

FIgURE 4. Membership function of TDFLS.

\subsection{Defuzzification method of TDFLS [5]}

Let $\tilde{A}=\left(a\left\{1-\rho\left(\frac{1}{k_{1}}-\frac{1}{n+1}\right)\right\}, a, a\left\{1+\sigma\left(\frac{1}{k_{2}}-\frac{1}{n+1}\right)\right\}\right)$ be a TDFLS with respect to the double keys $k_{1}$ and $k_{2}$. Then we construct the membership function $\mu(x)$ of $\tilde{A}$ as follows

$$
\mu(x)= \begin{cases}\frac{x-a\left\{1-\rho\left(\frac{1}{k_{1}}-\frac{1}{n+1}\right)\right\}}{a \rho\left(\frac{1}{k_{1}}-\frac{1}{n+1}\right)}, & a\left\{1-\rho\left(\frac{1}{k_{1}}-\frac{1}{n+1}\right)\right\} \leqslant x \leqslant a \\ \frac{a\left\{1+\sigma\left(\frac{1}{k_{2}}-\frac{1}{n+1}\right)\right\}-x}{a \sigma\left(\frac{1}{k_{2}}-\frac{1}{n+1}\right)}, & a \leqslant x \leqslant a\left\{1+\sigma\left(\frac{1}{k_{2}}-\frac{1}{n+1}\right)\right\} \\ 0, & \text { otherwise. }\end{cases}
$$

Therefore, the corresponding left and right $\alpha$-cuts are $L^{-1}(\alpha, n)=a\left\{1-\rho\left(\frac{1}{k_{1}}-\frac{1}{n+1}\right)\right\}+\alpha a \rho\left(\frac{1}{k_{1}}-\frac{1}{n+1}\right)$ and $R^{-1}(\alpha, n)=a\left\{1+\sigma\left(\frac{1}{k_{2}}-\frac{1}{n+1}\right)\right\}-\alpha a \sigma\left(\frac{1}{k_{2}}-\frac{1}{n+1}\right)$ respectively. Now, we find the ranking index value as $I(\tilde{A})=\frac{1}{2 N} \sum_{n=0}^{N} \int_{0}^{1}\left\{L^{-1}(\alpha, n)+R^{-1}(\alpha, n)\right\} \mathrm{d} \alpha$. So, $I(\tilde{A}) \rightarrow a\left\{1+\frac{1}{4}\left(\frac{\sigma}{k_{2}}-\frac{\rho}{k_{1}}\right)\right\}$ as $N \rightarrow \infty$. 


\subsection{Finding lock for single-key and double keys [5]}

When an uncertainty is present in a parameter, then the expert may not know the exact value but (s)he knows a bound of that parameter. Then, (s)he fixes a upper limit ( $a^{U}$, if known), lower limit $\left(a^{L}\right.$, if known) or both for that parameter.

For single key, if upper bound is available, then we get

$$
I(\tilde{a}) \leq a^{U} \text { implies } k \geq \frac{a(\sigma-\rho)}{4\left(a^{U}-a\right)} .
$$

If the lower bound is known, then we have

$$
I(\tilde{a}) \geq a^{L} \text { implies } k \geq \frac{a(\rho-\sigma)}{4\left(a-a^{L}\right)} .
$$

For double key, the index value of a TDFLN is

$$
\begin{aligned}
I(\tilde{A})=\frac{1}{2 N} \sum_{n=0}^{N} \int_{0}^{1}\left\{L^{-1}(\alpha, n)+R^{-1}(\alpha, n)\right\} \mathrm{d} \alpha & =\frac{a}{2}\left(1-\frac{\rho}{2 k_{1}}\right)+\frac{a}{2}\left(1+\frac{\sigma}{2 k_{2}}\right) . \text { So, } \\
\frac{a}{2}\left(1-\frac{\rho}{2 k_{1}}\right) & \geq a^{L} \text { implies } k_{1} \geq \frac{a \rho}{2\left(a-2 a^{L}\right)} \\
\text { and } \frac{a}{2}\left(1+\frac{\sigma}{2 k_{2}}\right) & \geq a^{U} \text { implies } k_{2} \geq \frac{a \sigma}{2\left(2 a^{U}-a\right)} .
\end{aligned}
$$

\section{Notations And Assumptions}

The following notations and assumptions are adopted to develop the proposed inventory model.

\subsection{Notations}

\section{Cases of supplier}

$\begin{array}{ll}A_{s i}, i=1,2 & \text { Set up cost of supplier } i\left(\mathrm{STC}_{s i}\right) . \\ h_{s i}, i=1,2 & \text { Holding cost of product } i . \\ s_{i}, i=1,2 & \text { Selling price of product } i \text { (purchasing price of product } i \text { by the retailer). } \\ K, K_{2} & \text { Production rate of supplier } 1 \text { and } 2 \text { respectively. } \\ c_{s i}, i=1,2 & \text { Production cost of product } i . \\ w_{s} & \text { Defective items treatment cost per unit item. } \\ p_{1} & \% \text { of defective item. }\end{array}$

\section{Cases of retailer}

$D_{i} \quad$ Demand rate of product $i$.

$s_{p i}, i=1,2 \quad$ Selling price of product $i$.

$A_{r i}, i=1,2 \quad$ Ordering cost of product $i\left(\mathrm{OC}_{I i}\right)$.

$c_{s c}$

Screening cost of product 1 per unit item.

$h_{p i}, i=1,2 \quad$ Holding cost of retailer for product $i$.

\section{Decision variables}

$m \quad$ Number of shipments.

$T_{1} \quad$ Time of substitution.

$T \quad$ Time of one production cycle. 


\subsection{Assumptions}

While developing the model, the following assumptions are made

(1) There are two suppliers with two different brand of items and one retailer.

(2) The retailer sells two brands of the product and each supplier supplies one brand.

(3) An arrival of items from supplier 1 may contain a fraction of defective items. After the arrival of an order, the retailer inspects and returns the defective items to the supplier 1 at the time of delivery of the next lot.

(4) Screening rate of item 1 is greater than its demand rate.

(5) To avoid shortage during the screening time, the number of good items is at least equal to demand during screening time implies: $p_{1}<1-\frac{D_{1}}{x}, x$ is the screening rate.

(6) Order from supplier 2 does not contain any imperfect items.

(7) The demand rate of both items are constant and unequal in general. Both items face their own demand.

(8) Substitution is allowed when the first item is out of stock and the second item replaces that immediately.

(9) The system operates for an infinite planning horizon.

\section{Formulation of the mathematical MODEL}

In this two-echelon supply chain, in a single set up the supplier 1 as well as supplier 2 produces $m Q_{1}$ and $m Q_{2}$ units respectively to reduce the production cost. During the production period, as soon as the first $Q_{1}$ units of item 1 and $Q_{2}$ units of item 2 have been produced, both supplier will deliver them to the retailer. The production process of item 1 may be imperfect. An arriving order from supplier 1 may contain some defective items with defective rate $p_{1}$ whereas supplier 2 confirms the retailer that there will be no defective items in own lots. By inspecting the items properly, supplier 2 sends item 2 to the retailer. So, upon the arrival of shipment, the retailer only inspect item 1 . After the screening process of item 1, the defective items will be returned to the supplier 1 at the time of delivery of the next lot.

After the joint replenishment, both items face their own demand and the demands can be met up by the perfect quality items. As a fraction $p_{1}$ of defective item is present in supplier 1's lot, the order quantity $\left(1-p_{1}\right) Q_{1}$ can not fulfill the demand of item 1 for the time $T$. After time $T_{1}$, the inventory of item 1 depletes to zero and its demand is subsequently satisfied by inventory of item 2 . At time $T$, the inventory of item 2 drops to zero and an instant joint replenishment for both items is triggered. The nature of the inventory level over time is shown in Figure 5.

\subsection{Supplier 1's total profit per unit time}

The holding cost for supplier $1\left(\mathrm{HC}_{s 1}\right)$ is given by

$$
\begin{aligned}
& =h_{s 1}\left[\left\{m Q_{1}\left(\frac{Q_{1}}{K}+(m-1) T\right)-\frac{m^{2} Q_{1}^{2}}{2 K}\right\}-Q_{1} T(1+2+\ldots+(m-1))\right] \\
& =h_{s 1}\left(\frac{m Q_{1}^{2}}{K}+\frac{m(m-1) Q_{1} T}{2}-\frac{m^{2} Q_{1}^{2}}{2 K}\right) \\
& \text { Sales revenue }\left(\mathrm{SR}_{s 1}\right)=s_{1} m Q_{1} \\
& \text { Production cost }\left(\mathrm{PC}_{s 1}\right)=c_{s 1} m Q_{1} \\
& \text { Defective items treatment cost }(\mathrm{DTC})=w_{s} p_{1} m Q_{1} .
\end{aligned}
$$

Therefore, supplier 1's total profit per production cycle can be expressed as

$$
\begin{aligned}
& \operatorname{TP}_{s 1}\left(m, Q_{1}\right)=\mathrm{SR}_{s 1}-\left(\mathrm{STC}_{s 1}+\mathrm{HC}_{s 1}+\mathrm{PC}_{s 1}+\mathrm{DTC}\right) \text { giving } \\
& \operatorname{TP}_{s 1}\left(m, Q_{1}\right)=\left(s_{1}-c_{s 1}\right) m Q_{1}-\left\{A_{s 1}+h_{s 1} m Q_{1}\left(\frac{m Q_{1}}{K}+\frac{(m-1) T}{2}-\frac{m Q_{1}}{2 K}\right)+w_{s} p_{1} m Q_{1}\right\} .
\end{aligned}
$$




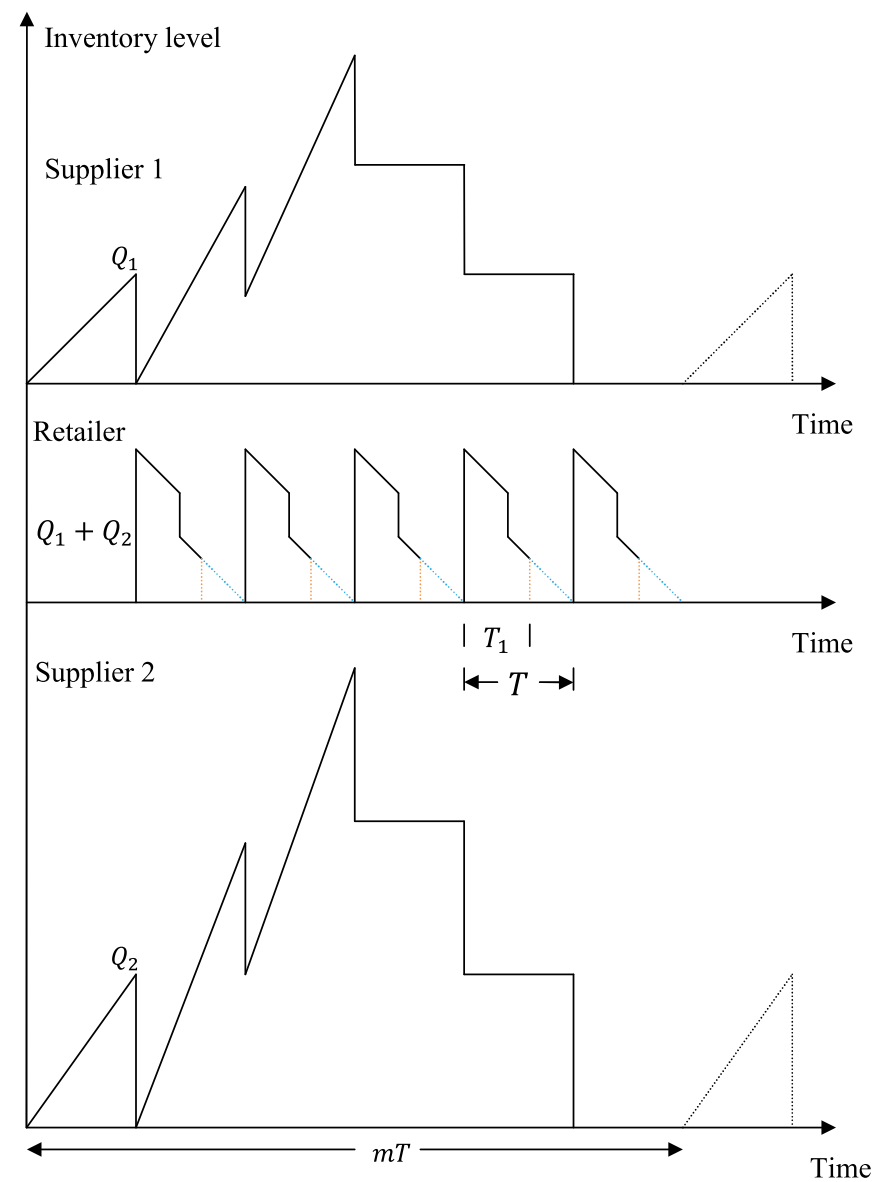

FIGURE 5. Integrated inventory model with defective and stock-out based substitution.

Substituting $Q_{1}=\frac{D_{1} T_{1}}{1-p_{1}}$ in (4.6), we get the total average profit per unit time for supplier 1 as

$$
\begin{aligned}
\operatorname{TAP}_{s 1}(m, T)= & \frac{\operatorname{TP}_{s 1}(m, T)}{m T}=\frac{\left(s_{1}-c_{s 1}\right) D_{1} T_{1}}{T\left(1-p_{1}\right)}-\frac{A_{s 1}}{m T} \\
& -\frac{w_{s} p_{1} D_{1} T_{1}}{T\left(1-p_{1}\right)}-\frac{h_{s 1} D_{1} T_{1}}{T\left(1-p_{1}\right)}\left\{\frac{D_{1} T_{1}}{K\left(1-p_{1}\right)}+\frac{(m-1) T}{2}-\frac{m D_{1} T_{1}}{2 K\left(1-p_{1}\right)}\right\} .
\end{aligned}
$$

\subsection{Supplier 2's total profit per unit time}

The holding cost of supplier $2\left(\mathrm{HC}_{s 2}\right)$ is given by

$$
=h_{s 2}\left\{\frac{m Q_{2}{ }^{2}}{K_{2}}+\frac{m(m-1) Q_{2} T}{2}-\frac{m^{2} Q_{2}{ }^{2}}{2 K_{2}}\right\}
$$

Sales revenue $\left(\mathrm{SR}_{s 2}\right)=s_{2} m Q_{2}$

Production cost $\left(\mathrm{PC}_{s 2}\right)=c_{s 2} m Q_{2}$. 


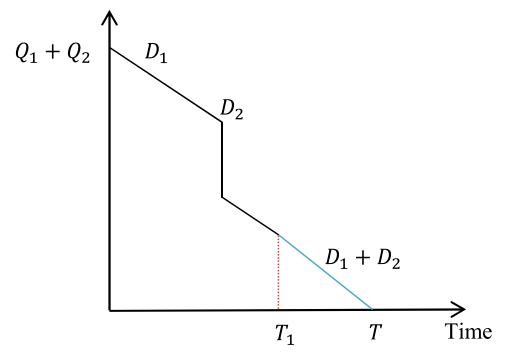

FiguRE 6. Retailer's inventory.

Therefore, supplier 2's total profit per production cycle can be expressed as

$$
\begin{aligned}
& \mathrm{TP}_{s 2}\left(m, Q_{2}\right)=\mathrm{SR}_{s 2}-\left(\mathrm{STC}_{s 2}+\mathrm{PC}_{s 2}+\mathrm{HC}_{s 2}\right) \text { which gives } \\
& \operatorname{TP}_{s 2}(m, Q)=\left(s_{2}-c_{s 2}\right) m Q_{2}-\left\{A_{s 2}+h_{s 2}\left(\frac{m Q_{2}{ }^{2}}{K_{2}}+\frac{m(m-1) Q_{2} T}{2}-\frac{m^{2} Q_{2}{ }^{2}}{2 K_{2}}\right)\right\} .
\end{aligned}
$$

Now, substituting $Q_{2}=\left(D_{1}+D_{2}\right) T-D_{1} T_{1}$, the total average profit per unit time becomes

$$
\begin{aligned}
\operatorname{TAP}_{s 2}(m, T)= & \frac{\operatorname{TP}_{s 2}(m, T)}{m T}=\left(s_{2}-c_{s 2}\right)\left(D_{1}+D_{2}-D_{1} \frac{T_{1}}{T}\right)-\frac{A_{s 2}}{m T}-h_{s 2}\left(D_{1}+D_{2}-D_{1} \frac{T_{1}}{T}\right) \\
& \times\left[\frac{\left(D_{1}+D_{2}\right) T-D_{1} T_{1}}{K_{2}}+\frac{m-1}{2}-\frac{\left\{\left(D_{1}+D_{2}\right) T-D_{1} T_{1}\right\}}{2 K_{2}}\right] .
\end{aligned}
$$

\subsection{Retailer's total profit per unit time}

The retailer receives an order of item 1 containing defective items with defective rate $p_{1}$, so the number of good items 1 in a lot is $=\left(1-p_{1}\right) Q_{1}$. On the time interval $\left[0, T_{1}\right]$, the governing differential equation of the production inventory (Fig. 6) is given by

$$
\begin{array}{ll}
\frac{\mathrm{d} I_{11}}{\mathrm{~d} t}=-D_{1} & 0 \leq t \leq T_{1}, I_{11}\left(T_{1}\right)=0 \\
\frac{\mathrm{d} I_{21}}{\mathrm{~d} t}=-D_{2} & 0 \leq t \leq T_{1}, I_{21}(0)=Q_{2} .
\end{array}
$$

During the time interval $\left[T_{1}, T\right]$, the variation of the inventory level of item 2 is given by

$$
\frac{\mathrm{d} I_{22}}{\mathrm{~d} t}=-D_{1}-D_{2} \quad T_{1} \leq t \leq T, \quad I_{22}(T)=0 .
$$

Utilizing the continuity at $T_{1}$, we have $I_{21}\left(T_{1}\right)=I_{22}\left(T_{1}\right)$ and get

$$
Q_{2}=\left(D_{1}+D_{2}\right) T-D_{1} T_{1}
$$

However, $I_{11}(0)=\left(1-p_{1}\right) Q_{1}$ gives

$$
Q_{1}=\frac{D_{1} T_{1}}{\left(1-p_{1}\right)}
$$

Solving (4.14), (4.15) and (4.16) we get

$$
\begin{aligned}
I_{11} & =D_{1}\left(T_{1}-t\right) . \\
I_{21} & =Q_{2}-D_{2} t . \\
\text { and } \quad I_{22} & =\left(D_{1}+D_{2}\right)(T-t) .
\end{aligned}
$$




\subsubsection{Item 1}

Sales revenue $\left(\mathrm{SR}_{I 1}\right)=s_{p 1}\left(1-p_{1}\right) Q_{1}$

Purchasing cost $\left(\mathrm{PC}_{I 1}\right)=s_{1} Q_{1}$

Screening cost $(\mathrm{SC})=c_{s c} Q_{1}$

Holding cost $\left(\mathrm{HC}_{I 1}\right)=h_{p 1} \int_{0}^{1} D_{1}(T-t) \mathrm{d} t=\frac{1}{2} D_{1} h_{p 1} T_{1}{ }^{2}$.

The total average profit for item 1 per unit time is given by

$$
\begin{aligned}
\mathrm{TAP}_{1} & =\mathrm{SR}_{I 1}-\left(\mathrm{OC}_{I 1}+\mathrm{HC}_{I 1}+\mathrm{PC}_{I 1}+\mathrm{SC}\right) \\
& =\frac{1}{T}\left[s_{p 1}\left(1-p_{1}\right) Q_{1}-s_{1} Q_{1}-c_{s c} Q_{1}-A_{r 1}-\frac{1}{2} D_{1} h_{p 1} T_{1}^{2}\right] .
\end{aligned}
$$

4.3.2. Item 2

Sales revenue $\left(\mathrm{SR}_{I 2}\right)=s_{p 2} Q_{2}$

Purchasing cost $\left(\mathrm{PC}_{I 2}\right)=s_{2} Q_{2}$

$$
\begin{aligned}
\text { Holding cost }\left(\mathrm{HC}_{I 2}\right) & =h_{p 2}\left[\int_{0}^{T_{1}}\left(Q_{2}-D_{2} t\right) \mathrm{d} t+\int_{T_{1}}^{T}\left(D_{1}+D_{2}\right)(T-t) \mathrm{d} t\right] \\
& =h_{p 2}\left[Q_{2} T_{1}-D_{2} \frac{T_{1}^{2}}{2}+\left(D_{1}+D_{2}\right)\left(\frac{T^{2}}{2}-T T_{1}+\frac{T_{1}^{2}}{2}\right)\right] .
\end{aligned}
$$

The total average profit for item 2 is given by

$$
\begin{aligned}
\operatorname{TAP}_{I 2} & =\mathrm{SR}_{I 2}-\left(\mathrm{OC}_{I 2}+\mathrm{HC}_{I 2}+\mathrm{PC}_{I 2}\right) \\
& =\frac{1}{T}\left[s_{p 2} Q_{2}-A_{r 2}-s_{2} Q_{2}-h_{p 2}\left\{Q_{2} T_{1}-D_{2} \frac{T_{1}^{2}}{2}+\left(D_{1}+D_{2}\right)\left(\frac{T^{2}}{2}-T T_{1}+\frac{T_{1}^{2}}{2}\right)\right\}\right] .
\end{aligned}
$$

Thus, the total average profit of the retailer becomes

$$
\begin{aligned}
\operatorname{TAP}_{r}= & \frac{1}{T}\left[s_{p 1}\left(1-p_{1}\right) Q_{1}-s_{1} Q_{1}-c_{s c} Q_{1}-A_{r 1}-\frac{1}{2} D_{1} h_{p 1} T_{1}^{2}+s_{p 2} Q_{2}-A_{r 2}\right. \\
& \left.-s_{2} Q_{2}-h_{p 2}\left\{Q_{2} T_{1}-D_{2} \frac{T_{1}^{2}}{2}+\left(D_{1}+D_{2}\right)\left(\frac{T^{2}}{2}-T T_{1}+\frac{T_{1}^{2}}{2}\right)\right\}\right] .
\end{aligned}
$$

Substituting $Q_{1}$ and $Q_{2}$ from (4.18) and (4.17) respectively, we get the equation (4.32) as

$$
\begin{aligned}
\operatorname{TAP}_{r}= & s_{p 1} D_{1} \frac{T_{1}}{T}-\frac{D_{1} s_{1} T_{1}}{\left(1-p_{1}\right) T}-\frac{A_{r 1}}{T}-\frac{c_{s c} D_{1} T_{1}}{T\left(1-p_{1}\right)}-\frac{h_{p 1}}{2}\left\{\frac{D_{1} T_{1}^{2}}{T}+\frac{p_{1} D_{1} T_{1}}{1-p_{1}}\right\} \\
& +\left(s_{p 2}-s_{2}\right)\left(D_{1}+D_{2}-D_{1} \frac{T_{1}}{T}\right)-\frac{A_{r 2}}{T}-h_{p 2}\left\{\left(D_{1}+D_{2}-D_{1} \frac{T_{1}}{T}\right) T_{1}\right. \\
& \left.+\left(D_{1}+D_{2}\right)\left(\frac{T}{2}-T_{1}\right)+\frac{D_{1} T_{1}^{2}}{2 T}\right\} .
\end{aligned}
$$




\subsection{Model of joint SC management}

Once the supplier and retailer have built up long-term cooperative relationship, they will jointly determine the best policy for the mutual benefits. Accordingly, the joint average profit per unit time for the integrated system is

$$
\begin{aligned}
z= & s_{p 2}\left(D_{1}+D_{2}-D_{1} \frac{T_{1}}{T}\right)-\frac{A_{r 2}}{T}-h_{p 2}\left\{\left(D_{1}+D_{2}-D_{1} \frac{T_{1}}{T}\right) T_{1}+\frac{D_{1} T_{1}^{2}}{2 T}\right. \\
& \left.+\left(D_{1}+D_{2}\right)\left(\frac{T}{2}-T_{1}\right)\right\}+s_{p 1} D_{1} \frac{T_{1}}{T}-\frac{A_{r 1}}{T}-\frac{c_{s c} D_{1} T_{1}}{T\left(1-p_{1}\right)}-\frac{h_{p 1}}{2}\left\{\frac{D_{1} T_{1}^{2}}{T}+\frac{p_{1} D_{1} T_{1}}{1-p_{1}}\right\} \\
& -\frac{c_{s 1} D_{1} \tau}{T\left(1-p_{1}\right)}-\frac{A_{s 1}}{m T}-\frac{w_{s} p_{1} D_{1} T_{1}}{T\left(1-p_{1}\right)}-\frac{A_{s 2}}{m T}-c_{s 2}\left(D_{1}+D_{2}-D_{1} \frac{T_{1}}{T}\right) \\
& -\frac{h_{s 1} D_{1} T_{1}}{T\left(1-p_{1}\right)}\left\{\frac{D_{1} T_{1}}{K\left(1-p_{1}\right)}+\frac{(m-1) T}{2}-\frac{m D_{1} T_{1}}{2 K\left(1-p_{1}\right)}\right\} \\
& -h_{s 2}\left(D_{1}+D_{2}-D_{1} \frac{T_{1}}{T}\right)\left\{\frac{\left(D_{1}+D_{2}\right) T-D_{1} T_{1}}{K_{2}}+\frac{m-1}{2}-\frac{\left\{\left(D_{1}+D_{2}\right) T-D_{1} T_{1}\right\}}{2 K_{2}}\right\} .
\end{aligned}
$$

Therefore, the final problem of the integrated profit per unit time becomes

$$
\left\{\begin{array}{l}
\text { Maximize } z\left(m, T_{1}, T\right) \\
\text { Subject to } Q_{1}=D_{1} T_{1} \\
Q_{2}=\left(D_{1}+D_{2}\right) T-D_{1} T_{1} \quad \text { for } 0<T_{1}<T
\end{array}\right.
$$

\subsection{Particular cases}

(1) No substitution. If we put $T_{1}=T$ and $p_{1}=0$ in our proposed model, then we get

$$
\begin{aligned}
z= & s_{p 2} D_{2}-\frac{A_{r 1}+A_{r 2}}{T}-\frac{1}{2} h_{p 2} D_{2} T+s_{p 1} D_{1}-c_{s c} D_{1}-\frac{1}{2} h_{p 1} D_{1} T \\
& -c_{s 1} D_{1}-\frac{A_{s 1}+A_{s 2}}{m T}-c_{s 2} D_{2}-h_{s 1} D_{1}\left\{\frac{D_{1} T}{K}+\frac{(m-1) T}{2}-\frac{m D_{1} T}{2 K}\right\} \\
& -h_{s 2} D_{2}\left\{\frac{D_{2} T}{2 K_{2}}+\frac{m-1}{2}\right\}
\end{aligned}
$$

which is the integrated supplier-retailer problem with no substitution.

(2) Full substitution. Assuming $T_{1}=0$ and $p_{1}=1$ in (4.35), the proposed model corresponds to the full substitution model. As item 1 is fully substituted by item 2, supplier 1 and inventory of item 1 will be absent here. Therefore, the full substitution inventory model becomes

$$
\begin{aligned}
z= & s_{p 2}\left(D_{1}+D_{2}\right)-\frac{A_{r 2}}{T}-\frac{1}{2} h_{p 2}\left(D_{1}+D_{2}\right) T-\frac{A_{s 2}}{m T}-c_{s 2}\left(D_{1}+D_{2}\right) \\
& -h_{s 2}\left(D_{1}+D_{2}\right)\left\{\frac{\left(D_{1}+D_{2}\right) T}{K_{2}}+\frac{m-1}{2}-\frac{\left(D_{1}+D_{2}\right) T}{2 K_{2}}\right\} .
\end{aligned}
$$

(3) If we assume supplier 2's and item 2's parameters are zero in (4.36)

$A_{s 2}, A_{r 2}, h_{s 2}, h_{p 2}, s_{p 2}, c_{s 2}, c_{s c}=0$ then (4.36) reduces to

$$
z=s_{p 1} D_{1}-\frac{A_{r 1}}{T}-\frac{1}{2} h_{p 1} D_{1} T-\frac{A_{s 1}}{m T}-h_{s 1} D_{1}\left\{\frac{D_{1} T}{K}+\frac{(m-1) T}{2}-\frac{m D_{1} T}{2 K}\right\} .
$$

The corresponding cost function (4.38) assumes value

$$
z^{\prime}=\frac{A_{r 1}}{T}+\frac{1}{2} h_{p 1} D_{1} T+\frac{A_{s 1}}{m T}+h_{s 1} D_{1}\left\{\frac{D_{1} T}{K}+\frac{(m-1) T}{2}-\frac{m D_{1} T}{2 K}\right\}
$$




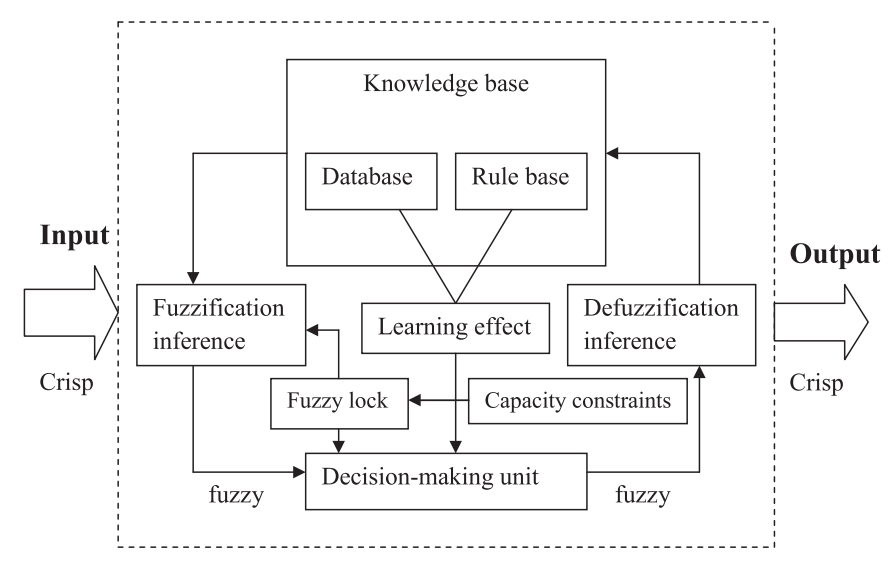

FiguRE 7. Schematic overview of the fuzzy model under TDFLS.

which is the basic supply chain problem with one supplier and one retailer.

(4) If we put the cost parameters associated with supplier 1 tending to zero, then

$$
z=\frac{A_{r 1}}{T}+\frac{1}{2} h_{p 1} D_{1} T
$$

which is the classical EOQ model.

\section{Implication of TDFLS in Supply Chain (SC) management}

The current research in application of fuzzy set is developed to capture the linguistic ambiguity in our day to day life. In decision-making problem, the ambiguity can be reduced through continuous practices. This kind of situation in inventory management problem basically dealt with through learning experiences. Incorporating the concept of learning experience in fuzzy set, the TDFS has been developed and which has the property to reduce the uncertainty. In practical situation, though learning experience has been applied, but it is impossible to predict the future situations exactly. Something might go wrong due to several constraints over complex situations. But the DM are intelligent enough to control the cost of the inventory of the supply chain as per situation arise. To deal with these kind of situation TDFLS plays an important role. In TDFLS, $\tilde{A}=\left(a\left\{1-\rho\left(\frac{1}{k}-\frac{1}{n+1}\right)\right\}, a, a\left\{1-\rho\left(\frac{1}{k}-\frac{1}{n+1}\right)\right\}\right)$ and the index $I(\tilde{A})=a\left\{1+\frac{\sigma-\rho}{4 k}\right\}$. Now, the DM can accept or reject a decision based on the situation by using the proper key $k$. Moreover, the fuzzy inference scheme based on dense fuzzy lock set is shown in Figure 7.

\section{FuZzy MAThematical MODEL}

Suppose, the parameters associated with (4.35) assume flexible values by nature. We assume the cost parameters of the problem namely, as TDFLS. We shall solve the problem with TDFLS over learning effects for single key and double key respectively. Recalling (4.34), the total average inventory profit is defined as:

$$
z=\sum_{i=1}^{2} c_{i} f_{i}-\sum_{j=3}^{14} c_{j} f_{j}
$$

where $c_{1}=s_{p 1}, c_{2}=s_{p 2}, c_{3}=A_{r 1}, c_{4}=A_{r 2}, c_{5}=h_{p 1}, c_{6}=h_{p 2}, c_{7}=c_{s c}$

$c_{8}=w_{s}, c_{9}=A_{s 1}, c_{10}=A_{s 2}, c_{11}=c_{s 1}, c_{12}=c_{s 2}, c_{13}=h_{s 1}, c_{14}=h_{s 2}$, 


$$
\text { and } \begin{aligned}
f_{1} & =D_{1} \frac{T_{1}}{T}, f_{2}=\left(D_{1}+D_{2}-D_{1} \frac{T_{1}}{T}\right), f_{3}=\frac{1}{T}=f_{4}, f_{7}=\frac{D_{1} T_{1}}{T\left(1-p_{1}\right)}, \\
f_{5} & =\frac{1}{2}\left\{\frac{D_{1} T_{1}^{2}}{T}+\frac{p_{1} D_{1} T_{1}}{1-p_{1}}\right\}, f_{8}=\frac{p_{1} D_{1} T_{1}}{T\left(1-p_{1}\right)}, f_{9}=\frac{1}{m T}=f_{10}, \\
f_{11} & =\frac{D_{1} T_{1}}{T\left(1-p_{1}\right)}, f_{12}=\left(D_{1}+D_{2}-D_{1} \frac{T_{1}}{T}\right), \\
f_{6} & =\left\{\left(D_{1}+D_{2}-D_{1} \frac{T_{1}}{T}\right) T_{1}+\frac{D_{1} T_{1}^{2}}{2 T}+\left(D_{1}+D_{2}\right)\left(\frac{T}{2}-T_{1}\right)\right\}, \\
f_{13} & =\frac{D_{1} T_{1}}{T\left(1-p_{1}\right)}\left\{\frac{D_{1} T_{1}}{K\left(1-p_{1}\right)}+\frac{(m-1) T}{2}-\frac{m D_{1} T_{1}}{2 K\left(1-p_{1}\right)}\right\}, \\
f_{14} & =\left(D_{1}+D_{2}-D_{1} \frac{T_{1}}{T}\right)\left\{\frac{\left(D_{1}+D_{2}\right) T-D_{1} T_{1}}{K_{2}}+\frac{m-1}{2}-\frac{\left\{\left(D_{1}+D_{2}\right) T-D_{1} T_{1}\right\}}{2 K_{2}}\right\} .
\end{aligned}
$$

Now we assume the cost vector moves towards a triangular dense fuzzy lock set and the corresponding fuzzy expected average profit function can be redefined as

$$
\tilde{z}=\sum_{i=1}^{2} \tilde{c_{i}} f_{i}-\sum_{j=3}^{14} \tilde{c_{j}} f_{j}
$$

where

$$
\tilde{c_{i}}= \begin{cases}\left(c_{i 0}\left\{1-\rho_{i}\left(\frac{1}{k_{1 i}}-\frac{1}{1+n}\right)\right\}, c_{i 0}, c_{i 0}\left\{1+\sigma_{i}\left(\frac{1}{k_{2 i}}-\frac{1}{1+n}\right)\right\}\right) & \text { for TDFLSDK } \\ \left.c_{i 0}\left\{1-\rho_{i}\left(\frac{1}{k_{i}}-\frac{1}{1+n}\right)\right\}, c_{i 0}, c_{i 0}\left\{1+\sigma_{i}\left(\frac{1}{k_{i}}-\frac{1}{1+n}\right)\right\}\right) & \text { for TDFLSSK } \\ \left.c_{i 0}\left\{1-\frac{\rho_{i}}{k_{1}}\right\}, c_{i 0}, c_{i 0}\left\{1+\frac{\sigma_{i}}{k_{2}}\right\}\right) & \text { for general fuzzy. }\end{cases}
$$

Here, we shall study the model under general fuzzy and dense fuzzy lock set approach for single key and double key vector.

\subsection{Solution Algorithm}

We develop the solution procedure of the proposed fuzzy model (6.4) for three different cases. Since lock plays a vital role in TDFLS, we shall solve the fuzzy model for TDFLSSK, TDFLSDK and general fuzzy environment.

Step 1. By using the defuzzification rule given in Section 2, we find the index value of problem (6.4) as

$$
\begin{array}{lc}
I(z)=\sum_{i=1}^{2} c_{i 0}\left\{1+\frac{\sigma_{i}-\rho_{i}}{4 k_{i}}\right\} f_{i}-\sum_{j=3}^{14} c_{j 0}\left\{1+\frac{\sigma_{j}-\rho_{j}}{4 k_{j}}\right\} f_{j} & \text { for TDFLSSK, } \\
I(z)=\sum_{i=1}^{2} c_{i 0}\left\{1+\frac{1}{4}\left(\frac{\sigma_{i}}{k_{2 i}}-\frac{\rho_{i}}{k_{1 i}}\right)\right\} f_{i}-\sum_{j=3}^{14} c_{j 0}\left\{1+\frac{1}{4}\left(\frac{\sigma_{j}}{k_{2 j}}-\frac{\rho_{j}}{k_{1 j}}\right)\right\} f_{j} \text { for TDFLSDK and general fuzzy. }
\end{array}
$$

Step 2. We find the key vector for all cost parameters for TDFLSSK, TDFLSDK following the constraints given in equations (2.3)-(2.6) in Section 2. For general fuzzy, the key vector can be chosen randomly.

Step 3. Substituting the value of the key vector in the index value of the profit function for each of the three environment, the defuzzified problem can be represented by

$$
\left\{\begin{array}{l}
\text { Maximize } I(z)=\sum_{i=1}^{2} c_{i 0}\left\{1+\frac{1}{4}\left(\frac{\sigma_{i}}{k_{2 i}}-\frac{\rho_{i}}{k_{1 i}}\right)\right\} f_{i}-\sum_{j=3}^{14} c_{j 0}\left\{1+\frac{1}{4}\left(\frac{\sigma_{j}}{k_{2 j}}-\frac{\rho_{j}}{k_{1 j}}\right)\right\} f_{j} \\
\text { Subject to } Q_{1}=\frac{D_{1} T_{1}}{1-p_{1}}, Q_{2}=\left(D_{1}+D_{2}\right) T-D_{1} T_{1} \text { for } 0<T_{1}<T .
\end{array}\right.
$$

For TDFLSSK, we put $k_{1 i}=k_{2 i}=k_{i}$.

Step 4. Optimize the problem (6.6) and get the optimal solution of the decision variables $m^{*}, T_{1}^{*}, T^{*}, Q_{1}^{*}, Q_{2}^{*}, z^{*}$ for TDFLSSK, TDFLSDK and general fuzzy models. 
TABLE 1. Optimal value of the key vectors.

\begin{tabular}{lcll}
\hline \hline Single key vector & Value & Double key vector & Value \\
\hline$k_{1}$ & 0.18 & $\left\{k_{13}, k_{23}\right\}$ & $\{0.065,0.065\}$ \\
$k_{2}$ & 3.01 & $\left\{k_{14}, k_{24}\right\}$ & $\{0.21,0.23\}$ \\
$k_{3}$ & 0.074 & $\left\{k_{11}, k_{21}\right\}$ & $\{0.52,0.072\}$ \\
$k_{4}$ & 0.018 & $\left\{k_{12}, k_{22}\right\}$ & $\{0.82,0.024\}$ \\
$k_{5}$ & 1.14 & $\left\{k_{15}, k_{25}\right\}$ & $\{2.88,0.31\}$ \\
$k_{6}$ & 1.08 & $\left\{k_{16}, k_{26}\right\}$ & $\{0.045,0.13\}$ \\
$k_{7}$ & 0.35 & $\left\{k_{17}, k_{27}\right\}$ & $\{2.19,0.15\}$ \\
$k_{8}$ & 0.89 & $\left\{k_{18}, k_{28}\right\}$ & $\{0.095,0.079\}$ \\
$k_{9}$ & 27.78 & $\left\{k_{19}, k_{29}\right\}$ & $\{425,0.13\}$ \\
$k_{10}$ & 114 & $\left\{k_{110}, k_{210}\right\}$ & $\{450,0.17\}$ \\
$k_{11}$ & 2.69 & $\left\{k_{111}, k_{211}\right\}$ & $\{0.87,0.23\}$ \\
$k_{12}$ & 0.64 & $\left\{k_{112}, k_{212}\right\}$ & $\{2.25,0.77\}$ \\
$k_{13}$ & 0.54 & $\left\{k_{113}, k_{213}\right\}$ & $\{0.42,0.13\}$ \\
$k_{14}$ & 1.29 & $\left\{k_{114}, k_{214}\right\}$ & $\{0.25,0.15\}$ \\
\hline
\end{tabular}

\section{Numerical EXAMPLES}

Let us take the following parametric values as $A_{r 1}=80, A_{r 2}=90, s_{p 1}=260, s_{p 2}=280, h_{p 1}=4.8$, $h_{p 2}=4.5, c_{s c}=8, w_{s}=7.6, A_{s 1}=100000, A_{s 2}=120000, c_{s 1}=50, c_{s 2}=40, h_{s 1}=4.7, h_{s 2}=4.3, D_{1}=200$, $D_{2}=90, K=300, K_{2}=150, p_{1}=.09$.

For TDFLS, we assume the $\rho_{i}$ 's and $\sigma_{i}$ 's as $\rho_{1}=0.01, \rho_{2}=0.06, \rho_{3}=0.13, \rho_{4}=0.11, \rho_{5}=0.48$, $\rho_{6}=0.01, \rho_{7}=0.27, \rho_{8}=0.03, \rho_{9}=0.17, \rho_{10}=0.15, \rho_{11}=0.07, \rho_{12}=0.45, \rho_{13}=0.009, \rho_{14}=0.08$ and $\sigma_{1}=0.2, \sigma_{2}=0.49, \sigma_{3}=0.53, \sigma_{4}=0.27, \sigma_{5}=0.67, \sigma_{6}=0.3, \sigma_{7}=0.34, \sigma_{8}=0.17, \sigma_{9}=0.27, \sigma_{10}=0.34$, $\sigma_{11}=0.5, \sigma_{12}=0.77, \sigma_{13}=0.3, \sigma_{14}=0.32$.

Now, the company has a certain budget range for every project/planning according to the market. So, the manufacturer/DM has a monetary range for every cost parameters upon which they will not exceed/lower the value. The upper and lower bound are given by: $A_{r 1 U}=188, A_{r 1 L}=35, A_{r 2 U}=294, A_{r 2 L}=42$, $s_{p 1 U}=330, s_{p 1 L}=120, s_{p 2 U}=290, s_{p 2 L}=120, h_{p 1 U}=5, h_{p 1 L}=2.2, h_{p 2 U}=4.8, h_{p 2 L}=2, c_{s c U}=8.5$, $c_{s c L}=3.8, w_{s U}=7.9, w_{s L}=3.2, A_{s 1 U}=100090, A_{s 1 L}=49990, A_{s 2 U}=120050, A_{s 2 L}=59990, c_{s 1 U}=52$, $c_{s 1 L}=24, c_{s 2 U}=45, c_{s 2 L}=18, h_{s 1 U}=5.2, h_{s 1 L}=2.1, h_{s 2 U}=4.5, h_{s 2 L}=1.8$.

Exploiting the equations (2.3)-(2.6) from Section 2, we determine the single key and double key vectors in Table 1.

Utilizing the solution algorithm (6.1), we get the solution given in Table 2.

Also, we have provided the optimal solution for the other two cases: no substitution and full substitution in Table 3.

\subsection{Discussion on numerical examples}

In crisp case, the total average profit is $\$ 51158.09$ with respect to the cycle time 7.1 months for the replenishment of item 1 and item 2 as 507.07 and 1597.27 units respectively. After 2.31 months cycle time, the inventory of item 1 becomes zero and substitution by item 2 is required.

From Table 2, we have observed that the general fuzzy solution of the model assumes higher profit than the crisp model as well as TDFLSSK model. The general fuzzy (\$75992.56) model increases the profit value and the order quantity of items are very less but the number of delivery increases to 10 times than crisp.

We have shown the result for TDFLSSK and TDFLSDK. The TDFLSDK gives larger profit than TDFLSSK. In TDFLS single key, the decision depends on one DM, so to be in the safer situation the decision will be subtle. But with double key double views, the risk, experiences will make the decision more stronger and higher. In 
TABLE 2. Optimal solution of the model.

\begin{tabular}{lllllll}
\hline \hline & $m$ & $z$ & $T_{1}$ & $T$ & $Q_{1}$ & $Q_{2}$ \\
\hline \multirow{4}{*}{ Crisp } & 3 & 50679.76 & 1.75 & 9.68 & 383.98 & 2458.83 \\
& $\mathbf{4}$ & $\mathbf{5 1 \mathbf { 1 5 8 . 0 9 }}$ & $\mathbf{2 . 3 1}$ & $\mathbf{7 . 1}$ & $\mathbf{5 0 7 . 0 7}$ & $\mathbf{1 5 9 7 . 2 7}$ \\
& 5 & 49972.96 & 2.55 & 5.66 & 559.58 & 1131.60 \\
\hline \multirow{3}{*}{ General fuzzy } & 45 & 75957.42 & 0.7 & 0.7 & 153.81 & 62.99 \\
& $\mathbf{4 6}$ & $\mathbf{7 5 9 9 2 . 5 6}$ & $\mathbf{0 . 5 2}$ & $\mathbf{0 . 7 6}$ & $\mathbf{1 1 3 . 5 0}$ & $\mathbf{1 1 6 . 0 1}$ \\
& 47 & 75967.04 & 0.67 & 0.67 & 147.79 & 60.52 \\
\hline \multirow{3}{*}{ TDFLSSK } & 22 & 58898.09 & 0.96 & 1.45 & 210.61 & 227.82 \\
& $\mathbf{2 3}$ & $\mathbf{5 8 9 3 2 . 6 6}$ & $\mathbf{0 . 9 2}$ & $\mathbf{1 . 3 9}$ & $\mathbf{2 0 2 . 8 2}$ & $\mathbf{2 1 8 . 3 0}$ \\
& 24 & 58532.07 & 1.20 & 1.20 & 264.16 & 108.17 \\
\hline \multirow{3}{*}{ TDFLSDK } & 48 & 78940.81 & 0.66 & 0.66 & 144.23 & 59.06 \\
& $\mathbf{4 9}$ & $\mathbf{8 0 7 4 7 . 3 7}$ & $\mathbf{0 . 4 9}$ & $\mathbf{0 . 7 1}$ & $\mathbf{1 0 6 . 7 6}$ & $\mathbf{1 0 8 . 7 9}$ \\
& 50 & 78945.53 & 0.63 & 0.63 & 138.93 & 56.89 \\
\hline
\end{tabular}

TABLE 3. Optimal solution of the model for particular cases.

\begin{tabular}{lllllll}
\hline \hline & $m$ & $z$ & $T_{1}$ & $T$ & $Q_{1}$ & $Q_{2}$ \\
\hline No substitution & 70 & 46855.41 & 0.44 & 0.44 & 87.61 & 39.43 \\
Full substitution & 176 & 66870.27 & 0 & 0.5 & $\ldots$ & 145.93 \\
\hline
\end{tabular}

TDFLSSK, the substitution time, cycle time, the quantity replenished of items is approximately double than in TDFLSDK. In Table 3, the profit in partial substitution is less than the profit in no substitution and greater than the profit in full substitution. So, from Table 3, we observe substitution benefits supplier-retailer.

In the whole table, TDFLSDK gives the best result among all other environments in terms of profit function as well as replenishment quantity of items. Also, we have observed that the profit function grows with the rise in number of deliveries of the system.

\section{SEnSitivity ANALYSIS}

We compute the values of the objective function (4.35) under the sensitivity of the parameters $\left\{D_{1}, D_{2}, K, K_{2}, p_{1}\right\}$ from $\{-30 \%$ to $+30 \%\}$ and this can be shown in the following Table 4 .

\subsection{Discussion on sensitivity analysis}

Table 4 shows the change in the profit function and other decision variables when a certain value in the parameter is being changed. A $+30 \%$ change in the demand of item 1 increases the profit by $25.75 \%$ as well as $-30 \%$ change reduces the profit by $-14.21 \%$. From the change in $D_{1}$ we see that with increment in $D_{1}$ from $-30 \%$ to $+30 \%$, the profit function and the replenishment quantity of item 1 is increasing. The nature of the parameter $D_{2}$ is approximately same as $D_{1}$ i.e. as the parametric value of $D_{2}$ increases the profit function grows. Likewise the parameter $D_{1}$, the parameter $D_{2}$ is also very sensitive. Now, the parameters $\left\{K, p_{1}\right\}$ are moderately sensitive and at any change in the parameters from $-30 \%$ to $+30 \%$, the change in profit assumes constant $(8.12 \%)$. The production rate of item $2, K_{2}$, shows a mix behavior. By $+30 \%$ change the profit increases $12.29 \%$ but at $-20 \%$ decrement there is negligible change in the profit function.

From the whole Table 4 , for the parameters $\left\{D_{1}, D_{2}, K_{2}\right\}$, the change from $-30 \%$ to $+30 \%$ the profit is increasing whether the parameters $K, p_{1}$ fixes the profit by $8.12 \%$. Most of the cases 3 deliveries or replenishment 
TABLE 4. Sensitivity Analysis of the EPQ model.

\begin{tabular}{lllllrrrr}
\hline \hline \multirow{2}{*}{ Parameter } & \% change & $m$ & $z$ & $T_{1}$ & \multicolumn{1}{c}{$T$} & \multicolumn{1}{c}{$Q_{1}$} & $Q_{2}$ & $\frac{z-z^{*}}{z^{*}} \times 100 \%$ \\
\hline \multirow{4}{*}{$D_{1}$} & +30 & 3 & 64332.4 & 1.62 & 8.42 & 462.94 & 2527.67 & 25.75 \\
& +20 & 3 & 61625.79 & 1.13 & 9.05 & 298.49 & 2716.26 & 20.46 \\
& -20 & 4 & 46012.47 & 1.34 & 8.57 & 235.49 & 1928.63 & -10.06 \\
& -30 & 4 & 43890.37 & 0.35 & 9.95 & 54.68 & 2239.32 & -14.21 \\
\hline \multirow{3}{*}{$D_{2}$} & +30 & 3 & 59960.64 & 0.81 & 9.57 & 178.78 & 2871.00 & 17.21 \\
& +20 & 3 & 58856.28 & 0.4 & 9.99 & 87.87 & 2998.72 & 15.05 \\
& -20 & 3 & 50714.42 & 0.0016 & 10.1 & 0.35 & 2745.97 & -0.87 \\
& -30 & 3 & 48453.23 & 0.0016 & 10.03 & 0.35 & 2636.76 & -5.29 \\
\hline \multirow{3}{*}{$K$} & +30 & 3 & 55310.45 & 0.0016 & 10.29 & 0.35 & 2984.32 & 8.12 \\
& +20 & 3 & 55310.45 & 0.0016 & 10.29 & 0.35 & 2984.32 & 8.12 \\
& -20 & 3 & 55310.45 & 0.0016 & 10.29 & 0.35 & 2984.32 & 8.12 \\
$K_{2}$ & -30 & 3 & 55310.45 & 0.0016 & 10.29 & 0.35 & 2984.32 & 8.12 \\
& +30 & 4 & 57447.97 & 0.0016 & 9.09 & 0.35 & 2634.54 & 12.29 \\
& +20 & 4 & 55380.22 & 0.83 & 8.28 & 181.95 & 2235.31 & 8.25 \\
& -20 & 3 & 51095.65 & 2.26 & 9.03 & 496.32 & 2167.91 & -0.12 \\
$p_{1}$ & -30 & 3 & 48639.05 & 3.38 & 8.45 & 743.03 & 1774.92 & -4.92 \\
& +30 & 3 & 55310.28 & 0.0016 & 10.29 & 0.37 & 2984.33 & 8.12 \\
& +20 & 3 & 55310.3 & 0.0016 & 10.29 & 0.37 & 2984.33 & 8.12 \\
& -20 & 3 & 55310.55 & 0.0016 & 10.29 & 0.36 & 2984.31 & 8.12 \\
& -30 & 3 & 55310.6 & 0.0016 & 10.29 & 0.34 & 2984.31 & 8.12 \\
\hline \multirow{3}{*}{} & & & & & & & &
\end{tabular}

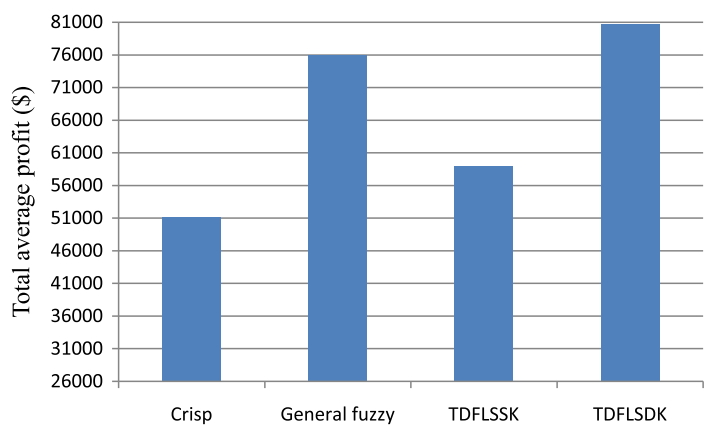

FiguRE 8. The total average profit for different models.

are sufficient to optimize the model. The parameter $D_{1}$ gives the maximum profit and the minimum profit for a $+30 \%$ change and $-30 \%$ change respectively.

\section{Graphical illustration}

Here we shall draw the graphs over the data set obtained in Tables 1-4.

Figure 8 shows the total average profit for different models. The profit function attains the larger value for TDFLSDK and lower value for crisp environment. Figures 9 and 10 correspond the replenishment quantity of item 1 and item 2 for different environments. The nature of the graphs 9 and 10 are approximately same. In crisp environment, order quantity carries maximum value whereas the other cases order quantity gets minimum value. Also, we observe the Figure 8 is completely opposite in nature to Figures 9 and 10. So, for the proposed model, less amount of order quantity maximizes the profit function. Figure 11 explores the deviation of the total 


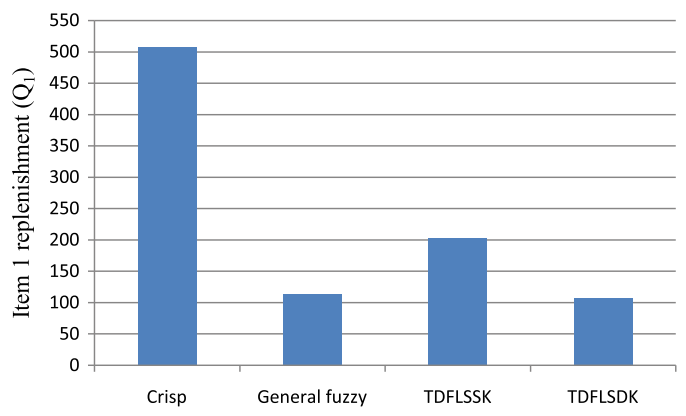

FiguRE 9. Item 1 replenishment for different models.

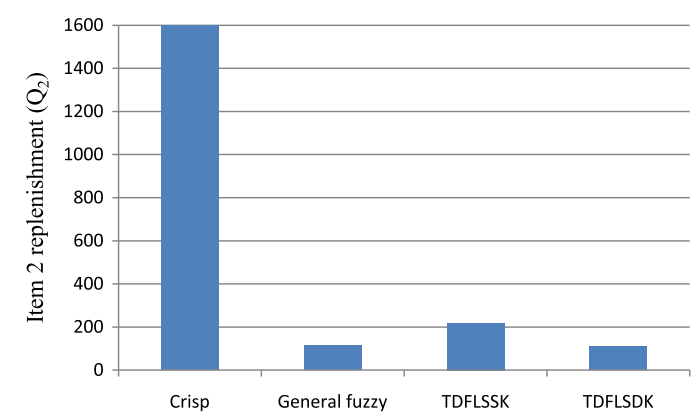

FigURE 10. Item 2 replenishment for different models.

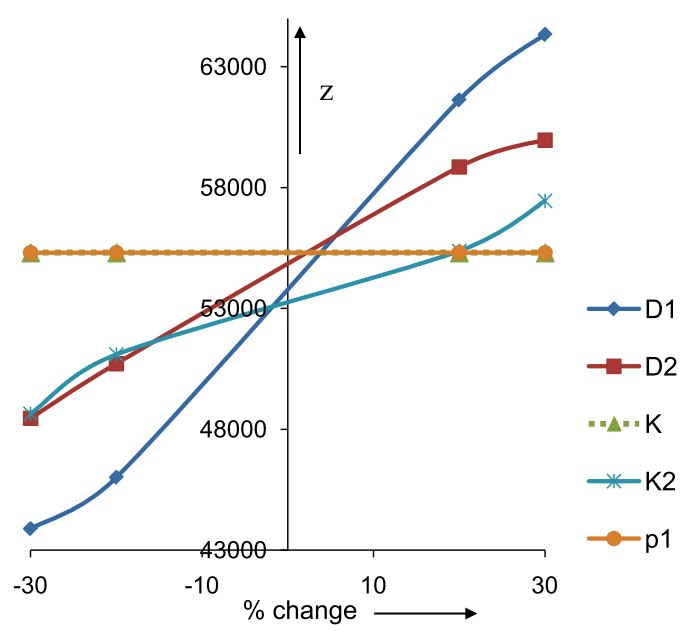

Figure 11. Average profit under $\%$ change in parameters.

average inventory profit with respect to the $\%$ change in the non-fuzzy parameters. A change in the parameters $\left\{D_{1}, D_{2}, K_{2}\right\}$ from $-30 \%$ to $+30 \%$, the curve of profit function is increasing and that for the parameter $K, p_{1}$; the curve remains constant. 


\section{Managerial insights}

From the numerical study we have seen that the TDFLSDK gives maximum profit with respect to the other models like crisp, general fuzzy and TDFLSSK. However, it is also seen that the order quantities of supplier I and supplier II are maximum for the case of crisp model but both of them getting minimized for the case of TDFLSDK. Also, the substitution time of order quantity and time of one production cycle assume minimum with respect to the model of single key. Beyond this, the basic nature of managerial insights for this study can be defined as follows:

- To avoid demand-supply mismatch stockout-based substitution is beneficial.

- Stock the product whose primary demand is zero because in stockout situation the secondary choice becomes the first choice of the customer.

- Substitution approach gives more profits to the inventory management system.

- Substitution raises inventory order quantity which is beneficial for the retailer.

- This model helps to maintain customer service commitment.

- To maintain democracy in managerial systems a scope has been opened for multiple keys of the fuzzy locks.

\section{Conclusion}

In this study we have developed an integrated supplier-retailer production inventory model considering stockout-based substitution. In the past literature, a considerable amount of work have been done in stochastic environment. In deterministic model, inventory with substitutable products are only available in EOQ or EPQ models. In this study, we develop a deterministic mathematical model for integrated inventory with two products substitution first. Then we have incorporated non random uncertainty in cost vectors and utilized the TDFLS rule for final decision making. We have analyzed the situation of no substitution, partial substitution and full substitution. Also, we have shown that substitution of items is profitable for the retailer. The inventory dealing with TDFLS is quite new. The application of TDFLS in inventory benefits both supplier and retailer as TDFLSDK gives the highest inventory profit for the proposed model.

However, this model has some limitations where imperfect items may be found during transportations or shipments. Also, for the case of full substitution the replenishment of supplier I's order quantity is less important for the retailer which is not useful for both the suppliers and retailer.

\section{Scope of future work}

This model can be extended to multi-suppliers, multi-retailer and also for multi-items supply chain modelling.

\section{Conflict of interest}

The authors declare that they have no conflict of interest regarding the publication of this article.

Acknowledgements. The authors are grateful to the anonymous reviewers and associate editor-in-cheif of this journal for valuable suggestions to improve the quality of this article.

\section{REFERENCES}

[1] A. Banerjee, A joint economic-lot-size model for purchaser and vendor. Decis. Sci. 17 (1986) $292-311$.

[2] L. Benkherouf, K. Skouri and I. Konstantaras, Inventory decisions for a finite horizon problem with product substitution options and time varying demand. Appl. Math. Model. 51 (2017) 669-685.

[3] J. Cai, P.R. Tadikamalla, J. Shang and G. Huang, Optimal inventory decisions under vendor managed inventory: substitution effects and replenishment tactics. Appl. Math. Model. 43 (2017) 611-629.

[4] X. Chen, Y. Feng, M.F. Keblis and J. Xu, Optimal inventory policy for two substitutable products with customer service objectives. Eur. J. Oper. Res. 246 (2015) 76-85.

[5] S.K. De, Triangular dense fuzzy lock sets. Soft Comput. 22 (2017) 7243-7254.

[6] S.K. De, On degree of fuzziness and fuzzy decision making. Cybern. Syst. 51 (2020) 600-614. 
[7] S.K. De and I. Beg, Triangular dense fuzzy sets and new defuzzification methods. J. Intel. Fuzzy Syst. 31 (2016) $469-477$.

[8] S.K. De and G.C. Mahata, Decision of a fuzzy inventory with fuzzy backorder model under cloudy fuzzy demand rate. Int. J. Appl. Comput. Math. 3 (2017) 2593-2609.

[9] S.K. De and G.C. Mahata, An EPQ model for three-layer supply chain with partial backordering and disruption: triangular dense fuzzy lock set approach. Sädhanā 44 (2019) 177.

[10] S.K. De and M. Pal, An intelligent decision for a bi-objective inventory problem. Int. J. Syst. Sci.: Oper. Logistics 3 (2016) 49-62.

[11] S.K. De and S.S. Sana, Fuzzy order quantity inventory model with fuzzy shortage quantity and fuzzy promotional index. Econ. Model. 31 (2013) 351-358.

[12] S.K. De and S.S. Sana, Multi-criterion multi-attribute decision-making for an EOQ model in a hesitant fuzzy environment. Pac. Sci. Rev. A: Nat. Sci. Eng. 17 (2015) 61-68.

[13] S.K. De and S.S. Sana, Two-layer supply chain model for cauchy-type stochastic demand under fuzzy environment. Int. J. Intel. Comput. Cybern. 11 (2018) 285-308.

[14] Z. Drezner, H. Gurnani and B.A. Pasternack, An EOQ model with substitutions between products. J. Oper. Res. Soc. 46 (1995) 887-891.

[15] S. Ghosh, S. Khanra and K. Chaudhuri, Optimal price and lot size determination for a perishable product under conditions of finite production, partial backordering and lost sale. Appl. Math. Comput. 217 (2011) 6047-6053.

[16] S.K. Goyal, "A joint economic-lot-size model for purchaser and vendor": a comment. Decis. Sci. 19 (1988) $236-241$.

[17] S.K. Goyal and Y.P. Gupta, Integrated inventory models: the buyer-vendor coordination. Eur. J. Oper. Res. 41 (1989) $261-269$.

[18] S.K. Goyal, C.K. Huang and K.C. Chen, A simple integrated production policy of an imperfect item for vendor and buyer. Prod. Planning Control 14 (2003) 596-602.

[19] H. Gurnani and Z. Drezner, Deterministic hierarchical substitution inventory models. J. Oper. Res. Soc. 51 (2000) $129-133$.

[20] J.T. Hsu and L.F. Hsu, An integrated vendor-buyer cooperative inventory model for items with imperfect quality and shortage backordering. Adv. Decis. Sci. 2012 (2012) 679083.

[21] G. Jamali, S.S. Sana and R. Moghdani, Hybrid improved cuckoo search algorithm and genetic algorithm for solving markovmodulated demand. RAIRO:OR 52 (2018) 473-497.

[22] S. Karmakar, S.K. De and A. Goswami, A pollution sensitive dense fuzzy economic production quantity model with cycle time dependent production rate. J. Cleaner Prod. 154 (2017) 139-150.

[23] R.S. Kumar, S. De and A. Goswami, Fuzzy EOQ models with ramp type demand rate, partial backlogging and time dependent deterioration rate. Int. J. Math. Oper. Res. 4 (2012) 473-502.

[24] S. Maity, S.K. De and S.P. Mondal, A study of a backorder EOQ model for cloud-type intuitionistic dense fuzzy demand rate. Int. J. Fuzzy Syst. 22 (2020) 201-211.

[25] R. Mcgillivray and E. Silver, Some concepts for inventory control under substitutable demand. INFOR: Info. Syst. Oper. Res. 16 (1978) 47-63.

[26] V.K. Mishra, Optimal ordering quantities for substitutable deteriorating items under joint replenishment with cost of substitution. J. Ind. Eng. Int. 13 (2017) 381-391.

[27] R. Moghdani, S.S. Sana and H. Shahbandarzadeh, Multi-item fuzzy economic production quantity model with multiple deliveries. 24 Soft Comput. (2020) 10363-10387.

[28] A. Mukhopadhyay and A. Goswami, An inventory model with shortages for imperfect items using substitution of two products. Int. J. Oper. Res. 30 (2017) 193-219.

[29] B. Pal, S.S. Sana and K. Chaudhuri, A three layer multi-item production-inventory model for multiple suppliers and retailers. Econ. Model. 29 (2012) 2704-2710.

[30] M. Parlar and S. Goyal, Optimal ordering decisions for two substitutable products with stochastic demands. Opsearch 21 (1984) 1-15.

[31] B.A. Pasternack and Z. Drezner, Optimal inventory policies for substitutable commodities with stochastic demand. Nav. Res. Logistics (NRL) 38 (1991) 221-240.

[32] M.K. Salameh and M.Y. Jaber, Economic production quantity model for items with imperfect quality. Int. J. Prod. Econ. 64 (2000) 59-64.

[33] S.S. Sana, A production-inventory model of imperfect quality products in a three-layer supply chain. Decis. Supp. Syst. 50 (2011) 539-547.

[34] S.S. Sana, Optimal contract strategies for two stage supply chain. Econ. Model. 30 (2013) 253-260.

[35] S.S. Sana, J.A. Chedid and K.S. Navarro, A three layer supply chain model with multiple suppliers, manufacturers and retailers for multiple items. Appl. Math. Comput. 229 (2014) 139-150.

[36] B. Sarkar, Supply chain coordination with variable backorder, inspections, and discount policy for fixed lifetime products. Math. Prob. Eng. 2016 (2016) 6318737.

[37] B. Sarkar and I. Moon, An EPQ model with inflation in an imperfect production system. Appl. Math. Comput. 217 (2011) 6159-6167.

[38] S. Sinha, N.M. Modak and S.S. Sana, An entropic order quantity inventory model for quality assessment considering price sensitive demand. Opsearch $\mathbf{5 7}(2020)$ 88-103.

[39] H.N. Soni and K.A. Patel, Optimal strategy for an integrated inventory system involving variable production and defective items under retailer partial trade credit policy. Decis. Supp. Syst. 54 (2012) 235-247. 
[40] M.A. Takami, R. Sheikh and S.S. Sana, A hesitant fuzzy set theory based approach for project portfolio selection with interactions under uncertainty. J. Inf. Sci. Eng. 34 (2018) 65-79.

[41] C.S. Tang and R. Yin, Joint ordering and pricing strategies for managing substitutable products. Prod. Oper. Manage. 16 (2007) 138-153.

[42] S. Transchel, Inventory management under price-based and stockout-based substitution. Eur. J. Oper. Res. 262 (2017) 996-1008.

[43] R. Uthayakumar and M. Palanivel, An inventory model for defective items with trade credit and inflation. Prod. Manuf. Res. 2 (2014) 355-379.

[44] H.M. Wee, J. Yu and M.C. Chen, Optimal inventory model for items with imperfect quality and shortage backordering. Omega 35 (2007) 7-11.

[45] L. Zadeh, Fuzzy sets. Inf. Control 8 (1965) 338-353. 